\title{
Health-related quality of life is strongly associated with self-efficacy, self-esteem, loneliness, and stress in 14-15-year-old adolescents: a cross-sectional study
}

Hilde Timenes Mikkelsen ${ }^{1 *}\left(\mathbb{0}\right.$, Kristin Haraldstad ${ }^{1}$, Sølvi Helseth ${ }^{1,2}$, Siv Skarstein², Milada Cvancarova Småstuen ${ }^{1,2}$ and Gudrun Rohde ${ }^{1,3}$

\begin{abstract}
Background: To enhance and better understand health-related quality of life (HRQOL) in adolescents, it is important to study factors associated with HRQOL. The present study aimed to assess possible associations between sociodemographic variables, self-efficacy, self-esteem, pain, sleep, loneliness, stress and HRQOL in 14 to 15-year-old adolescents.

Methods: A cross-sectional study was performed among 696 adolescents (14-15 years) in a school-based setting. Sociodemographic variables, self-efficacy, self-esteem, pain, sleep, loneliness and stress were analyzed. The variables were all assessed with well-validated instruments. HRQOL was analyzed using KIDSCREEN 27. Analyses included Chisquare, independent t-tests, Mann-Whitney $\mathrm{U}$ tests, linear regression analyses and hierarchical regression analyses. The results from linear regression models were expressed as standardized beta.

Results: The adolescents generally reported high levels of HRQOL. However, girls scored significantly worse on HRQOL, self-efficacy, self-esteem, pain, sleep, loneliness and stress compared to boys. Using hierarchical regression analyses we found that Self-efficacy (beta $=0.11-0.24$ ), Self-esteem: (beta $=0.12-0.21$ ), Loneliness: (beta $=-0.24$ to -0.45 ) and Stress: (beta $=-0.26$ to -0.34 ) revealed the strongest associations with the HRQOL dimensions. Sociodemographic-, pain- and sleep related covariates were all significantly associated with some of the KIDSCREEN subscales, however their effect on the outcome was smaller than for the psychosocial variables listed above. Being a girl, not living with both parents, not having both parents working, being absent from school more than 4 days, having pain and having lack of enough sleep were all independently negatively associated with HRQOL.

Conclusions: HRQOL is strongly associated with self-efficacy, self-esteem, loneliness and stress in 14 to 15-year-old adolescents. Our findings indicate that positive psychosocial factors such as self-efficacy and self-esteem might play a buffer role for negative psychosocial factors (e.g. stress) in adolescents. Further, our results show that girls score significantly worse on factors that are associated to HRQOL compared to boys. To improve HRQOL in school-based populations of adolescents, we suggest that future interventions should aim to strengthen self-efficacy and self-esteem. We recommend gender specific interventions.
\end{abstract}

Keyword: Health-related quality of life, Adolescents, Self-efficacy, Self-esteem, Loneliness, Stress

*Correspondence: hilde.e.mikkelsen@uia.no

${ }^{1}$ Department of Health and Nursing, Faculty of Health and Sport Sciences, University of Agder, Postbox 422, 4604 Kristiansand, Norway

Full list of author information is available at the end of the article

\section{Introduction}

Quality of life (QOL) is an important concept and target for research and practice in the fields of health and medicine [1]. The term "health-related quality of life" original author(s) and the source, provide a link to the Creative Commons licence, and indicate if changes were made. The images or other third party material in this article are included in the article's Creative Commons licence, unless indicated otherwise in a credit line to the material. If material is not included in the article's Creative Commons licence and your intended use is not permitted by statutory regulation or exceeds the permitted use, you will need to obtain permission directly from the copyright holder. To view a copy of this licence, visit http://creativecommons.org/licenses/by/4.0/. The Creative Commons Public Domain Dedication waiver (http://creativeco mmons.org/publicdomain/zero/1.0/) applies to the data made available in this article, unless otherwise stated in a credit line to the data. 
(HRQOL) is a multidimensional construct that includes the individual's subjective perspectives on the physical, psychological, social, and functional aspects of health [2]. The World Health Organization (WHO) emphasizes well-being and HRQOL as goals for public health, especially among adolescents, and underlines the need for research to identify the key determinants for health problems in this age group [3]. Moreover, WHO notes that adolescent health and well-being are essential for healthier and more sustainable societies $[4,5]$.

Adolescence is a life phase between childhood and adulthood in which the opportunities for health are great and where future patterns of adult health are established [4-7]. It is also a vulnerable period in life, and can be challenging with respect to independence from caregivers, increase of autonomy and social role transitions [5, $6,8-11]$. Although the vast majority of Norwegian adolescents are content with their lives and generally report good health [16], an increasing number of adolescents in Norway and other countries report psychosocial problems and health complaints in everyday life such as loneliness, stress, insufficient and poor-quality sleep, pain and high intake of over-the-counter analgesics (OTC analgesics) $[9,11-20]$, indicating a need for continued efforts in health promotion among adolescents.

Research has identified variables associated with HRQOL such as gender and age. HRQOL often declines during adolescence, and girls tend to report lower HRQOL than boys [16, 21-27]. Family, parents, and siblings are important for adolescents' HRQOL $[8,15,28]$, and HRQOL have been observed to be generally lower in those with low socioeconomic status (SES) and poor social support [29-31]. Furthermore, studies have shown that positive psychosocial factors such as self-efficacy and self-esteem have a positive impact on HRQOL in adolescence [22, 25, 31-34], while health-related and negative psychosocial factors such as stress, pain, high intake of OTC analgesics, loneliness, school absenteeism and insufficient and poor-quality sleep are associated with lower HRQOL among adolescents [12, 16, 17, 22, 23, 30, 35-39].

From a health promotion perspective, more knowledge of how sociodemographic variables, self-efficacy, self-esteem, pain, sleep, loneliness and stress are related to adolescents' HRQOL is needed. In order to gain more knowledge of which of these factors future interventions among school-based populations of adolescents should prioritize, there is a need to simultaneously investigate the impact of these factors on HRQOL. Investigating such associations could inform practice and policy. Furthermore, considering that age is an important predictor of HRQOL, more knowledge about HRQOL in adolescents at a specific age is warranted.
The aim of this study was to assess the associations between sociodemographic variables, self-efficacy, selfesteem, pain, sleep, loneliness, stress, and HRQOL in 14-15-year-old adolescents. Based on theory and earlier research, we hypothesized that there is a positive association between self-efficacy, self-esteem and HRQOL, and that there is a negative association between low SES, female gender, stress, loneliness, pain, higher school absenteeism, lack of sleep and HRQOL.

\section{Methods}

\section{Sample and data collection}

This cross-sectional study was a part of the "Start Young - quality of life and pain in generations" study, which is a longitudinal study that aims to acquire new knowledge about HRQOL and pain in adolescents and their parents, as well as investigate potential family and regional patterns. The present study used data collected at baseline. The Start Young study was conducted in the southeastern part of Norway, with approximately 1.6 million inhabitants (30\% of the total Norwegian population) and an adolescent population (aged 14-15 years) of approximately 37,000 . Schools covering 9 th grade (aged 14-15 years) in elementary school were stratified according to region, rural and urban districts, and school size. Two schools were randomly selected from each stratum. The schools were each sent a letter of invitation, followed by a telephone call to the school's principal. Schools that did not choose to participate were replaced by alternative schools selected according to the same criteria. We invited 59 schools and 22 schools agreed to participate. The schools varied in size and localization (from city to suburb) and admitted adolescents with different sociocultural and economic backgrounds. Inclusion criteria for this study were being a student in $9^{\text {th }}$ grade at one of the participating schools, having active informed consent to participate from one parent, giving their own consent to participate and being present at school by the time of data collection. Potential participants in the study were 1663 adolescents in 9th grade from the participating schools of which 967 adolescents were excluded due to lack of active informed consent from parents $(n=872)$, not giving their own consent to participate $(n=8)$, technical problems at one school $(n=10)$ or because they were not present at school by the time of data collection $(n=77)$. A total of 696 adolescents took part (response rate $41.8 \%$ ). The response rate varied across schools from 92.1 to $8.6 \%$.

One or two project members visited each school approximately 1 week before data collection to provide the adolescents with verbal and written information about the study. Written information was also distributed to the parents. Active informed consent 
was obtained from both adolescents and their parents. Data collection was conducted from November 2018 to April 2019. A web-based questionnaire was administered and completed in the classrooms during school hours. One or two project members and a teacher were present to provide assistance when needed. The collected data were stored at a safe data server.

The "Start Young-quality of life and pain in generations" study was reviewed by the Norwegian Centre for Research Data (Ref: 60,981). Necessary approvals were obtained.

\section{Instruments}

\section{Demographic variables}

The first part of the questionnaire included selfreported data on demographic variables such as gender, date of birth, cohabitant status, parental marital status, parents' birthplace, whether the respondents had moved during the previous 5 years, and school absence.

\section{Questionnaires}

A list of instruments used in this study is presented in Table 1.The internal consistency for multi-item scales was assessed using Cronbach's alpha [40].

$H R Q O L$ was measured using the Norwegian version of the KIDSCREEN-27 questionnaire [41, 42]. The KIDSCREEN-27 is a well-validated, short, multidimensional measure of generic HRQOL in children and adolescents organized into five subscales: (1) Physical well-being; (2) Psychological well-being; (3) Autonomy and parent relations; (4) Social support and peers; and (5) School environment [41, 43-45]. The KIDSCREEN instrument is answered on a 5-point Likert scale referring to the last week. The scale indicates either the frequency of certain behaviors or feelings (ranging from "never" to "always") or the intensity of an attitude (ranging from "not at all" to "extremely"). Rasch scores were computed for each subscale and transformed into $\mathrm{t}$-values as described in the KIDSCREEN manual [45]. The resulting $\mathrm{t}$-values can be used to make comparisons with international $t$-values based on 14 European countries. These values are normed to a mean of 50 and a standard deviation of 10 [45].

Table 1 Overview of instruments used in this study

\begin{tabular}{|c|c|c|c|}
\hline Factors & Instruments & Number of items & $a^{a}$ \\
\hline \multirow[t]{6}{*}{ HRQOL } & KIDSCREEN-27 & & \\
\hline & Physical well-being & 5 & 0.81 \\
\hline & Psychological well-being & 7 & 0.87 \\
\hline & Autonomy and parent relations & 7 & 0.77 \\
\hline & Social support and peers & 4 & 0.78 \\
\hline & School environment & 4 & 0.80 \\
\hline Self-efficacy & Generalized Self-Efficacy Scale (GSE) & 10 & 0.87 \\
\hline Self-esteem & Rosenberg Self-Esteem scale (RSES) & 4 & 0.79 \\
\hline \multirow[t]{11}{*}{ Pain } & Brief Pain Inventory (BPI) & & \\
\hline & Having pain today & 1 & \\
\hline & Pain on average & 1 & \\
\hline & Pain interference with activity & 3 & 0.81 \\
\hline & Pain interference with emotions & 4 & 0.90 \\
\hline & Lübeck Pain-Screening Questionnaire (LPQ) & & \\
\hline & Pain duration & 1 & \\
\hline & Pain frequency & 1 & \\
\hline & OTC analgesic questions (derived from SUS) & & \\
\hline & Intake of OTC analgesics during the last 4 weeks & 1 & \\
\hline & Frequency of OTC analgesics intake & 1 & \\
\hline \multirow[t]{3}{*}{ Sleep } & School Sleep Habits Survey & & \\
\hline & Problems with sleepiness & 1 & \\
\hline & Frequency of enough sleep & 1 & \\
\hline Loneliness & UCLA Loneliness Scale (ULS-8) & 8 & 0.80 \\
\hline Stress & Perceived Stress Questionnaire (PSQ) & 30 & 0.93 \\
\hline
\end{tabular}

OTC, Over-the-counter; SUS, "Pain, youth and self-medication study"

aCronbach's a coefficient values in this study 
The answers were recoded so that higher values always indicate better HRQOL in the respective subscales. The Norwegian version of the instrument has been demonstrated to be reliable and valid [42].

Self-efficacy was measured using the Norwegian version of the Generalized Self-Efficacy Scale (GSE) that measures optimistic self-beliefs in coping with the demands, tasks, and challenges of life in general $[46,47]$. The GSE consists of 10 statements that the respondent rates on a scale from 1 (completely wrong) to 4 (completely right). The respondent's scores on each item are summed and divided by ten to a GSE score ranging from 1-4, with higher scores indicating higher levels of generalized self-efficacy. The GSE has been shown reliable and valid $[34,46]$.

Self-esteem was measured using a short version of the Rosenberg Self-Esteem scale (RSES) [48], wherein respondents rate four statements on self-perceptions on a 4-point Likert scale ranging from 1 (strongly disagree) to 4 (strongly agree). The answers were recoded so that higher values always indicate higher levels of self-esteem. The respondent's scores on each item were summed and divided by 4 into an RSES score ranging from 1-4. The Norwegian four-item version has demonstrated a high degree of correlation (0.95) with the 10-item version [49] and has been used among adolescents [50, 51].

Pain was measured using the Brief Pain Inventory (BPI) $[52,53]$ and selected questions from the Lübeck PainScreening Questionnaire (LPQ) [54]. The BPI assesses the subjective intensity of pain and to what extent pain interferes with activity and emotions [52, 53]. Pain interference questions were only administered to those who rated $\geq 1$ on the "pain on average" question (indicating that they had pain). The Norwegian BPI has satisfactory psychometric properties [53], and it has previously been used among Norwegian adolescents [55]. Respondents who rated $\geq 1$ on the "pain on average" question of the BPI were also administered two follow-up questions from the LPQ referring to pain duration and pain frequency. The LPQ is a structured self-report questionnaire that evaluates the prevalence and consequences of pain [54]. The Norwegian LPQ has satisfactory feasibility, content, and face validity [56]. Finally, two questions derived from the Norwegian "Pain, youth and self-medication study" (SUS) $[17,57]$ were used to measure the intake of OTC analgesics. The study involved adolescents through a three-step process in the questionnaire development [17, 57]. In our study, the respondents were first asked about OTC analgesic intake during the last 4 weeks. If the answer was "yes," the respondents were asked about the frequency of intake.

Sleep was measured using two questions adapted from the School Sleep Habits Survey [58], one focusing on problems with sleepiness during daily activities and one focusing on frequency of enough sleep. The School Sleep Habits Survey has been widely used for adolescents and has an established validity in comparison to sleep diaries and actigraphy [59]. It has previously been used to assess sleep habits in Norwegian adolescents [60].

Loneliness was measured using the eight-item version of the revised UCLA Loneliness Scale (ULS-8) [61]. This instrument is a short version of the widely used 20-item revised UCLA Loneliness Scale (ULS-20) [62] and is considered to be a reliable and adequate measure of loneliness among adolescents [63]. ULS-8 uses a 4-point Likert scale with values ranging from "never" to "always." The total score ranges from 8 to 32 points, with higher scores suggesting a higher degree of loneliness. Previous studies have recommended ULS-8 as a good substitute for the ULS-20 [61, 63, 64]. The ULS-8 questionnaire was translated into Norwegian as part of this study by using standardized translation procedures according to an international cross-cultural translation manual, which includes forward and backward translations, pre-testing, and cognitive interviews [65]. The reliability of the ULS-8 Norwegian version was verified using the Cronbach's alpha coefficient, which in this study was 0.80 , suggesting good internal consistency for the instrument [40].

Stress was measured using the Perceived Stress Questionnaire (PSQ) [66-68]. PSQ is a 30-item questionnaire referring to the last 4 weeks and can be answered with a 4-point rating scale ranging from 1 (almost never) to 4 (almost always). The answers were recoded so that higher values always indicate higher levels of perceived stress. The resulting PSQ total score was linearly transformed between 0 and $1 ; \mathrm{PSQ}=($ raw value-30)/90 [66]. Commonly used cutoff levels of stress with respect to the PSQ are low $<0.33$, medium $0.33-0.45$, moderate $0.45-0.60$, and severe $>0.60$. The Norwegian version of the instrument has been demonstrated to have good reliability and validity $[68,69]$.

\section{Data analyses}

Descriptive statistics were calculated for all variables according to gender and presented as means and standard deviation or as median and $\mathrm{min} / \mathrm{max}$ for continuous variables. Categorical variables were presented as counts and percentages. Associations between pairs of variables were assessed using chi-square test for categorical data. For continuous data, the $t$-test were used for normal distributed data and Mann-Whitney $U$ test were used for data that did not follow normal distribution. The study used an electronic survey tool which was designed to consecutively administer the following respective questionnaires. The adolescents were free to end the survey at 
any time. Most questions included a neutral option. This resulted in all items being answered.

The five KIDSCREEN subscales were selected as the dependent variables for further analyses. The selected covariates were grouped into seven blocks (B1-B7); B1: Sociodemographic variables, B2: Self-efficacy, B3: Selfesteem, B4: Pain on average, B5: Frequency of enough sleep, B6: Loneliness, and B7: Stress. All selected covariates were theoretically known clinically relevant variables reported in previous HRQOL research [8, 22, 23, 25, $30,33,38$. To assess possible associations between the covariates in each block and HRQOL, linear regression analyses were fitted separately for each of the five KIDSCREEN subscales. Assumptions for linear regression were checked and fulfilled. Residuals followed normal distribution.

To further assess possible adjusted associations with HRQOL, hierarchical regression analyses were conducted (method enter) for the five KIDSCREEN subscales. The covariates were entered into the regression in seven steps based on B1-B7. Seven linear regression models (M1-M7) were fitted for each of the KIDSCREEN subscales by adding variables from a previous model (block) consecutively; later models always included the variables from the previous steps. All tests were two-sided. P-values $\leq 0.01$ were considered statistically significant in order to adjust for multiple testing. All analyses were performed using IBM SPSS Statistics (version 26).

\section{Results}

\section{Characteristics of the sample}

Tables 2 and 3 show the sample characteristics for all included variables. In total, 696 participants (57.5\% girls) with a median age of 14 years were included in the analyses. In total, more than two thirds of the participants lived with both parents, had parents who were both born in Norway, had parents who were both working, and had 1-2 siblings. There were no statistically significant differences between genders concerning any of the analyzed sociodemographic variables (Table 2 ).

Regarding the descriptive characteristics presented in Table 3, several variables significantly differed according to gender. The adolescents generally reported high levels of HRQOL assessed using the KIDSCREEN-27 scores, but girls reported significantly lower levels of HRQOL than boys for the subscales Physical well-being, Psychological well-being, and School environment. Moreover, girls reported significantly lower levels of Self-efficacy and Self-esteem and higher levels of Loneliness and Stress than boys. Significantly more girls (36.0\%) than boys (18.9\%) reported Having pain today, and the levels of Pain on average and Pain interference with emotions were also significantly higher for girls than boys. Further, significantly more girls $(59.9 \%)$ than boys $(34.8 \%)$ reported Intake of OTC analgesics during the last 4 weeks. Among those who rated $\geq 1$ for Pain on average (76\%), more than one third of the adolescents reported Pain duration of more than 3 months (persistent pain) and 34.7\% experienced pain often. More than two thirds of the adolescents reported getting enough sleep usually or always. However, significantly more girls than boys reported having Problems with sleepiness and less frequently getting enough sleep.

Crude associations between sociodemographic variables, self-efficacy, self-esteem, pain, sleep, loneliness, stress, and HRQOL examined by linear regression analyses

Multiple linear regression analyses were used to assess possible associations between selected variables and HRQOL. The strength of the associations between the covariates in each block (B1-B7) and the dependent variables (five KIDSCREEN subscales) is further described in terms of the effect sizes (standardized beta) and explained variance (Table 4). The psychosocial variables (Self-efficacy, Self-esteem, Loneliness, and Stress) had the largest effects on the outcome for all HRQOL dimensions. Self-efficacy and Self-esteem were positively associated with HRQOL whereas Stress and Loneliness were negatively associated. Sociodemographic- (B1), pain- (B4), and sleep-related covariates (B5) were all significantly associated with some of the subscales; however, their effect on the outcome was smaller than that of the psychosocial variables listed above. Being a girl, not living with both parents, not having both parents working, being absent from school more than 0-4 days, having pain, and lacking enough sleep were all independently negatively associated with HRQOL. The explained variance was the highest for Psychological well-being (the covariate Stress explained 51.8\%) and lowest for Physical well-being (the covariate Self-esteem explained 19.2\%).

\section{Adjusted associations between sociodemographic variables, self-efficacy, self-esteem, pain, sleep, loneliness, stress, and HRQOL examined by hierarchical regression analyses}

Table 5 shows the strength of the adjusted associations from the hierarchical regression analyses between the covariates and the dependent variables described in terms of effect sizes (standardized beta) and explained variance. When all variables were added into model 7 , the impact of the sociodemographic variables was diminished compared with the impact from the other covariates. However, Gender had the third largest effect size in relation to Autonomy and parent relations. Being a girl was positively associated with this KIDSCREEN 
Table 2 Characteristics of the sample $(\mathrm{N}=696)$

\begin{tabular}{|c|c|c|c|c|}
\hline Variable & Total (696) & Boys $(n=296)$ & Girls $(n=400)$ & $P$ value \\
\hline Age, mean (SD) & $14.09(0.33)$ & $14.08(0.36)$ & $14.09(0.30)$ & 0.905 \\
\hline Adult members of the household, $\mathrm{N}(\%)$ & & & & 0.185 \\
\hline Both parents & $508(73.0)$ & $224(75.7)$ & $284(71.0)$ & \\
\hline Alternates between two parents & $100(14.4)$ & $45(15.2)$ & $55(13.8)$ & \\
\hline One parent and one stepparent & $20(2.9)$ & $6(2.0)$ & $14(3.5)$ & \\
\hline One parent & $55(7.9)$ & $16(5.4)$ & $39(9.8)$ & \\
\hline Other caregivers & $13(1.9)$ & $5(1.7)$ & $8(2.0)$ & \\
\hline Parents' marital status, N (\%) ${ }^{\mathrm{a}}$ & & & & 0.642 \\
\hline Two parent family & $492(70.7)$ & $212(71.6)$ & $280(70.0)$ & \\
\hline Single/divorced parent family & $204(29.3)$ & $84(28.4)$ & $120(30.0)$ & \\
\hline Parents' birthplace, N (\%) & & & & 0.267 \\
\hline Both parents born in Norway & $551(79.2)$ & $241(81.4)$ & $310(77.5)$ & \\
\hline One parent born in Norway & $87(12.5)$ & $30(10.1)$ & $57(14.2)$ & \\
\hline Both parents born in another country & $58(8.3)$ & $25(8.4)$ & $33(8.3)$ & \\
\hline Parents' work status, N (\%) & & & & 0.013 \\
\hline Both parents working & $547(78.6)$ & $247(83.4)$ & $300(75.0)$ & \\
\hline One parent working & $133(19.1)$ & $46(15.5)$ & $87(21.8)$ & \\
\hline No parent working & $16(2.3)$ & $3(1.0)$ & $13(3.3)$ & \\
\hline Number of siblings, $\mathrm{N}(\%)^{\mathrm{b}}$ & & & & 0.730 \\
\hline None & $30(4.3)$ & $11(3.7)$ & $19(4.8)$ & \\
\hline 1 & $263(37.8)$ & $107(36.1)$ & $156(39.0)$ & \\
\hline 2 & $244(35.1)$ & $109(36.8)$ & $135(33.8)$ & \\
\hline$\geq 3$ & $159(22.8)$ & $69(36.8)$ & $90(22.5)$ & \\
\hline Moved during the previous 5 years, $\mathrm{N}(\%)^{c}$ & & & & 0.027 \\
\hline No & $474(68.1)$ & $215(72.6)$ & $259(64.8)$ & \\
\hline Yes & $222(31.9)$ & $81(27.4)$ & $141(35.3)$ & \\
\hline School absence for the previous 3 months, $\mathrm{N}(\%)^{\mathrm{d}}$ & & & & 0.812 \\
\hline $0-4$ days & $595(85.5)$ & $255(86.1)$ & $340(85.0)$ & \\
\hline 5-10 days & 84 (12.1) & 35 (11.8) & 49 (12.3) & \\
\hline$>10$ days & $17(2.4)$ & $8(2.0)$ & $11(2.8)$ & \\
\hline
\end{tabular}

Continuous variables analyzed using independent $t$-test. Categorical variables analyzed using $\mathrm{x}^{2}$-test

$\mathrm{SD}$, standard deviation

a The variable was dichotomized as "two parents" (married or cohabiting) or "single parent" (unmarried, divorced, or widowed)

b The variable was recoded into four categories: "none," "1," 2 ," or " $\geq 3$ " $(3,4,5,>5)$

c The variable was dichotomized as "yes" (moved 1 time, 2-4 times, $\geq 5$ times) or "no."

d The variable was recoded into three categories: "0-4 days" (none, 1-4 days), "5-10 days" (5-7 days, 8-10 days), or "> 10 days."

subscale. The psychosocial variables (Self-efficacy, Selfesteem, Loneliness, and Stress) revealed the largest effect sizes and also contributed to a considerable increase of the explained variance for all five subscales, suggesting that the psychosocial variables are highly relevant for adolescents' HRQOL. Self-efficacy and Self-esteem were positively associated with HRQOL, whereas Stress and Loneliness were negatively associated. Pain on average had a significant negative effect on four KIDSCREEN subscales; however, its effect on the outcome was smaller than that of the psychosocial variables. Frequency of enough sleep had the second largest significant effect on
Physical well-being (lacking enough sleep was negatively associated with HRQOL) but was no longer significantly associated with the other KIDSCREEN subscales when adjusted for available confounders. Given the analyzed variables, the explained variance of model 7 was the highest for Psychological well-being $(65.8 \%)$ and the lowest for Physical well-being (30.8\%).

\section{Discussion}

The aim of this cross-sectional study was to assess possible associations between sociodemographic variables, self-efficacy, self-esteem, pain, sleep, loneliness, stress, 
Table 3 Descriptive characteristics for HRQOL, self-efficacy, self-esteem, pain, sleep, loneliness, and stress ( $N=696)$

\begin{tabular}{|c|c|c|c|c|}
\hline Variable & Total $(n=696)$ & Boys $(n=296)$ & Girls $(n=400)$ & $P$ value \\
\hline Physical well-being, mean (SD) ${ }^{a, b}$ & $47.1(9.3)$ & $49.6(9.6)$ & $45.2(8.6)$ & $<0.001^{*}$ \\
\hline Psychological well-being, mean (SD) ${ }^{a, b}$ & $46.6(8.4)$ & $49.5(8.1)$ & $44.4(8.0)$ & $<0.001^{*}$ \\
\hline Autonomy and parent relations, mean (SD) $)^{a, b}$ & $52.6(8.7)$ & $53.4(9.1)$ & $51.9(8.5)$ & 0.027 \\
\hline Social support and peers, mean (SD) ${ }^{a, b}$ & $48.4(8.5)$ & $49.0(8.5)$ & $48.0(8.4)$ & 0.130 \\
\hline School environment, mean (SD) & $48.0(8.6)$ & $49.6(9.1)$ & $46.8(7.9)$ & $<0.001^{*}$ \\
\hline Self-efficacy, mean $(S D)^{c}$ & $3.1(0.4)$ & $3.2(0.4)$ & $3.0(0.4)$ & $<0.001^{*}$ \\
\hline Self-esteem, mean (SD) ${ }^{d}$ & $3.1(0.7)$ & $3.3(0.6)$ & $2.9(0.7)$ & $<0.001^{*}$ \\
\hline Having pain today, N (\%) & & & & $<0.001^{*}$ \\
\hline Yes & $200(28.7)$ & $56(18.9)$ & $144(36.0)$ & \\
\hline No & $496(71.3)$ & $240(81.1)$ & $256(64)$ & \\
\hline Pain on average, mean (SD) ${ }^{e}$ & $2.2(1.9)$ & $1.6(1.7)$ & $2.6(1.9)$ & $<0.001^{*}$ \\
\hline Pain interference with activity, median $(\min , \max )^{f, g}$ & $1.3(0.0,10.0)$ & $1.0(0.0,10.0)$ & $1.3(0.0,9.7)$ & 0.372 \\
\hline Pain interference with emotions, median (min, max) ${ }^{f, g}$ & $1.2(0.0,9.7)$ & $0.7(0.0,9.2)$ & $1.2(0.0,9.7)$ & $<0.001^{*}$ \\
\hline Pain duration, $\mathrm{N}(\%)^{\mathrm{f}, \mathrm{h}}$ & & & & 0.069 \\
\hline Pain $\leq 3$ months & $335(63.6)$ & $133(68.6)$ & $202(60.3)$ & \\
\hline Pain $>3$ months & $192(36.4)$ & $61(31.4)$ & $131(39.3)$ & \\
\hline Pain frequency, $\mathrm{N}(\%)^{\mathrm{f}, \mathrm{i}}$ & & & & 0.146 \\
\hline Seldom & $221(41.9)$ & $92(47.4)$ & $129(38.7)$ & \\
\hline Sometimes & $123(23.2)$ & $42(21.6)$ & $81(24.3)$ & \\
\hline Often & $183(34.7)$ & $60(30.9)$ & $123(36.9)$ & \\
\hline OTC analgesic intake during the last 4 weeks, N (\%) & & & & $<0.001^{*}$ \\
\hline Yes & $342(49.2)$ & $103(34.8)$ & 239 (59.9) & \\
\hline No & $353(50.8)$ & $193(65.2)$ & $160(40.1)$ & \\
\hline Frequency of OTC analgesic intake, $\mathrm{N}(\%)^{\mathrm{j}}$ & & & & 0.043 \\
\hline Daily & $20(5.8)$ & $10(9.7)$ & $10(4.2)$ & \\
\hline Every week, but not daily & $52(15.2)$ & $10(9.7)$ & $42(17.6)$ & \\
\hline Less often than every week & $243(71.1)$ & $72(69.9)$ & $171(71.5)$ & \\
\hline No intake during the last 4 weeks & $27(7.9)$ & $11(10.7)$ & $16(6.7)$ & \\
\hline Problems with sleepiness, N (\%) & & & & $<0.001^{*}$ \\
\hline No problem at all & $280(40.3)$ & $151(51.0)$ & $129(32.3)$ & \\
\hline A slight problem & $311(44.7)$ & $120(40.5)$ & $191(47.9)$ & \\
\hline More than a slight problem & $68(9.8)$ & $17(5.7)$ & $51(12.8)$ & \\
\hline A big problem & $26(3.7)$ & $7(2.4)$ & $19(4.8)$ & \\
\hline A very big problem & $10(1.4)$ & $1(0.3)$ & $9(2.3)$ & \\
\hline Frequency of enough sleep, N (\%) & & & & $0.002^{*}$ \\
\hline Always & $59(8.5)$ & $34(11.5)$ & $25(3.6)$ & \\
\hline Usually & $387(55.7)$ & $175(59.1)$ & $212(53.1)$ & \\
\hline Sometimes & $177(25.5)$ & $69(23.3)$ & $108(27.1)$ & \\
\hline Rarely & $63(9.1)$ & $15(5.1)$ & $48(6.9)$ & \\
\hline Never & $9(1.3)$ & $3(1.0)$ & $6(1.5)$ & \\
\hline Loneliness, median $(\min , \max )^{k}$ & $13.0(8.0,32.0)$ & $12.0(8.0,27.0)$ & $13.0(8.0,32.0)$ & $<0.001^{*}$ \\
\hline Stress, mean (SD) $)^{\prime}$ & $0.29(0.15)$ & $0.24(0.13)$ & $0.33(0.16)$ & $<0.001^{*}$ \\
\hline
\end{tabular}

Continuous variables analyzed using independent $t$-test and Mann-Whitney $U$ test. Categorical variables analyzed using $x^{2}$-test HRQOL, health-related quality of life; OTC, over-the-counter; SD, standard deviation

${ }^{a}$ KIDSCREEN subscales

${ }^{b}$ Rasch scores were computed for each subscale and transformed into t-values with a mean of 50 and an SD of 10 . Higher values indicate higher levels of HRQOL

c Range 1-4, where higher values indicate higher levels of self-efficacy

d Range 1-4, where higher values indicate higher levels of self-esteem

e Range 0-10, where 10 indicates pain as bad as you can imagine 
Table 3 (continued)

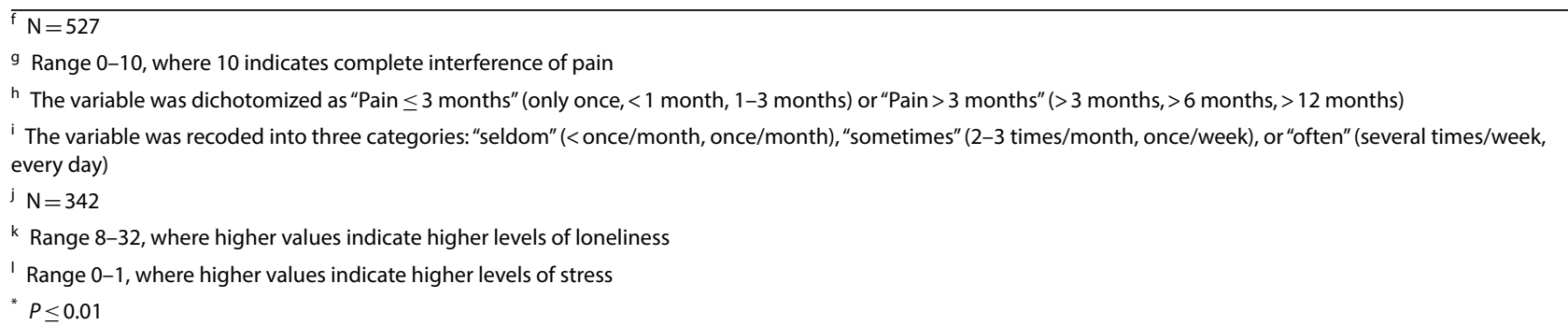

and HRQOL in 14-15-year-old adolescents. We found that 14-15-year-old Norwegian adolescents generally report levels of HRQOL that are in line with the results of the European Normdata for KIDSCREEN-27 in 12-18year old adolescents [45]. However, in line with previous research [21-27], our data confirmed that girls reported lower HRQOL than boys. One of the main findings in this study was that the psychosocial variables (Self-efficacy, Self-esteem, Loneliness, and Stress) had the largest effects on the outcome for all HRQOL dimensions both before and after adjustment for selected covariates. Sociodemographic-, pain-, and sleep-related covariates were all significantly associated with some of the subscales; however, their effect on the outcome was smaller than that of the psychosocial variables listed above.

According to our results, stress may be one of the greatest risk factors for adolescents' HRQOL. Moreover, our findings indicate that this may be especially important to consider in girls, because they reported having medium levels of stress compared with boys who only reported low values of stress. A Norwegian study by Moksnes and colleagues showed that girls had significantly higher mean scores on all stress domains and on emotional states compared with boys, who had higher self-esteem [7]. Additionally, our findings indicate that loneliness should also be considered as an important risk factor due to its large effect size for the KIDSCREEN subscale Social support and peers. Adolescence is considered a period of high risk for loneliness $[9,11]$, and failure to resolve loneliness before the end of adolescence may pose significant concerns for future social relationships and mental health [11].

Our findings highlight the importance of considering high self-efficacy and self-esteem as important protective or resource factors for HRQOL in adolescents, which is in line with previous research $[8,22,25,31-34]$. Moreover, our results show that in the presence of self-efficacy and self-esteem, the negative effect of stress on HRQOL decreases. Similar to the findings of Freire and Ferreira [22], this indicates that positive psychosocial factors (e.g., self-efficacy and self-esteem) might play a buffer role for negative psychosocial factors (e.g., stress) in adolescents.
This study revealed that many adolescents experienced pain, and girls reported significantly more pain than boys. The intensity of pain reported is not considered high, yet the prevalence is a cause for concern. Even though pain was not found to be a strong explanatory factor for variations in HRQOL, our results support previous research showing that pain is negatively associated with HRQOL in adolescents [16, 23]. Furthermore, we found that approximately half of the adolescents reported intake of OTC analgesics, and more girls than boys reported such intake. Considering the relatively low intensity of pain reported, this might indicate that the adolescents use OTC analgesics for reasons other than only pain relief. Frequent consumption of OTC analgesics may cause health problems such as drug-induced headache and liver failure [70]; thus, our findings emphasize that the use of OTC analgesics among adolescents should be regarded as a significant health concern. According to Skarstein et al. [70], informing adolescents, parents, and the society in general about how to use OTC analgesics appropriately should be a high priority.

Sleep played an important role for the dimension Physical well-being in our study, confirming that sleep is highly important for HRQOL in adolescents [19, 20, 39]. Studies have shown that there are several barriers to healthy sleep among adolescents such as later preferred sleep timing, lower parental supervision of bedtime, longer study time, and early school start time $[19,38,71]$. Thus, prevention of and interventions against sleep problems require collaboration between adolescents, parents, schools, and healthcare professionals [39].

After adjusting for other factors related to HRQOL, gender was statistically significantly associated only with Autonomy and parent relations. An interesting finding was also that being a girl was positively associated with this subscale. Possible explanations of our results might be that gender is important to HRQOL, but that part of the differences between boys and girls in HRQOL can be explained by psychosocial factors. Also, our results show that girls scored significantly worse on pain- and sleep related factors which also are associated with HRQOL. 


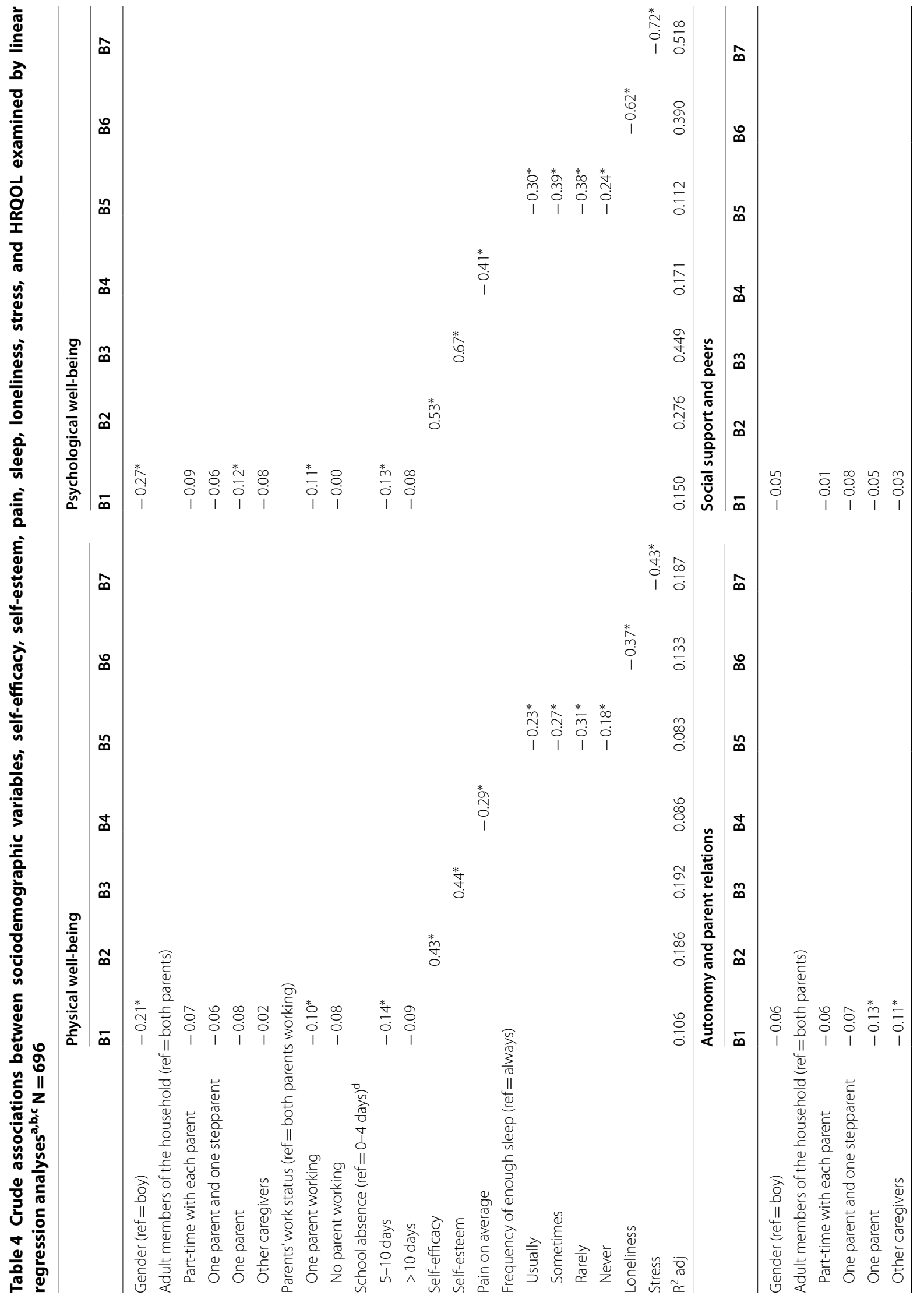




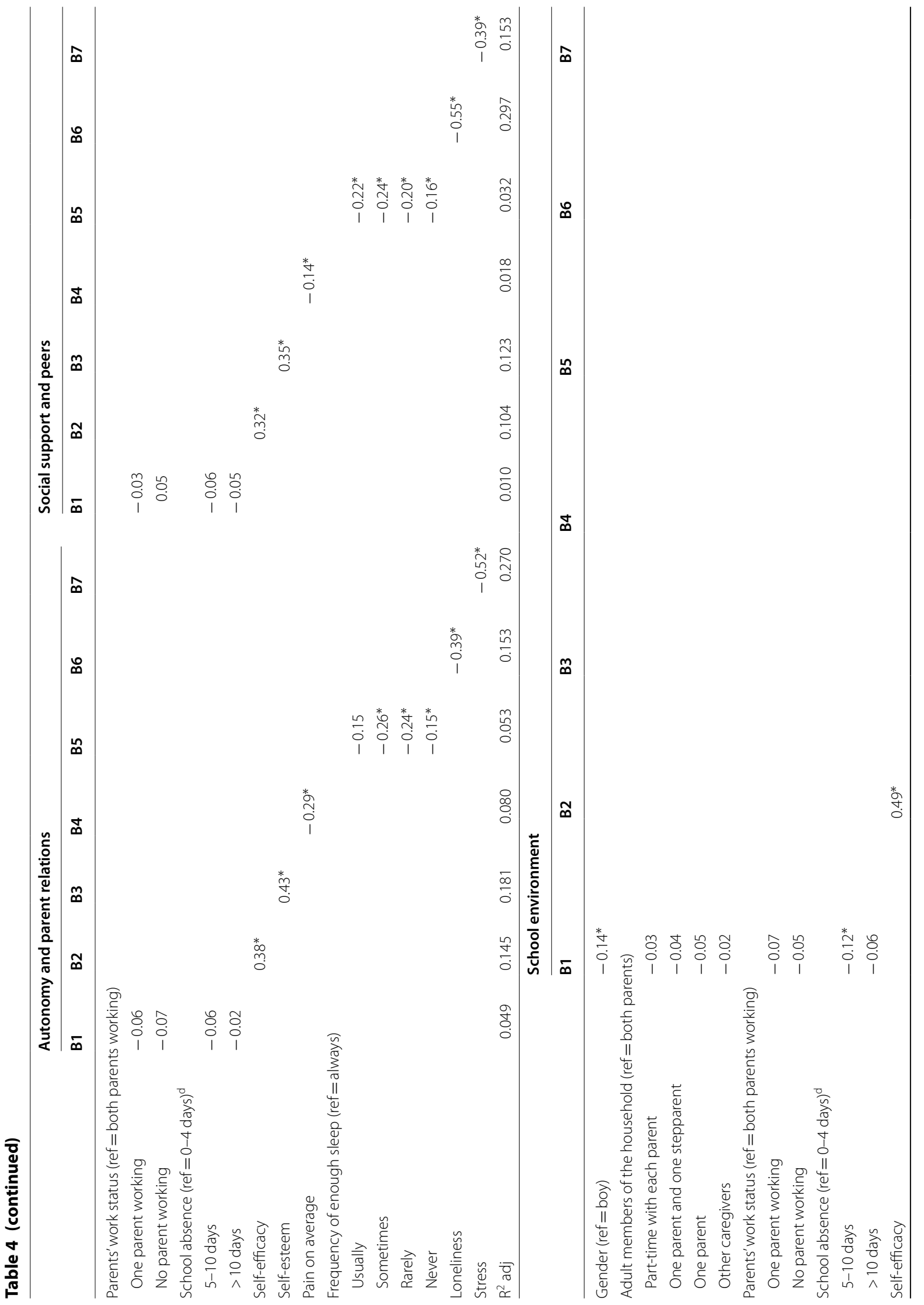




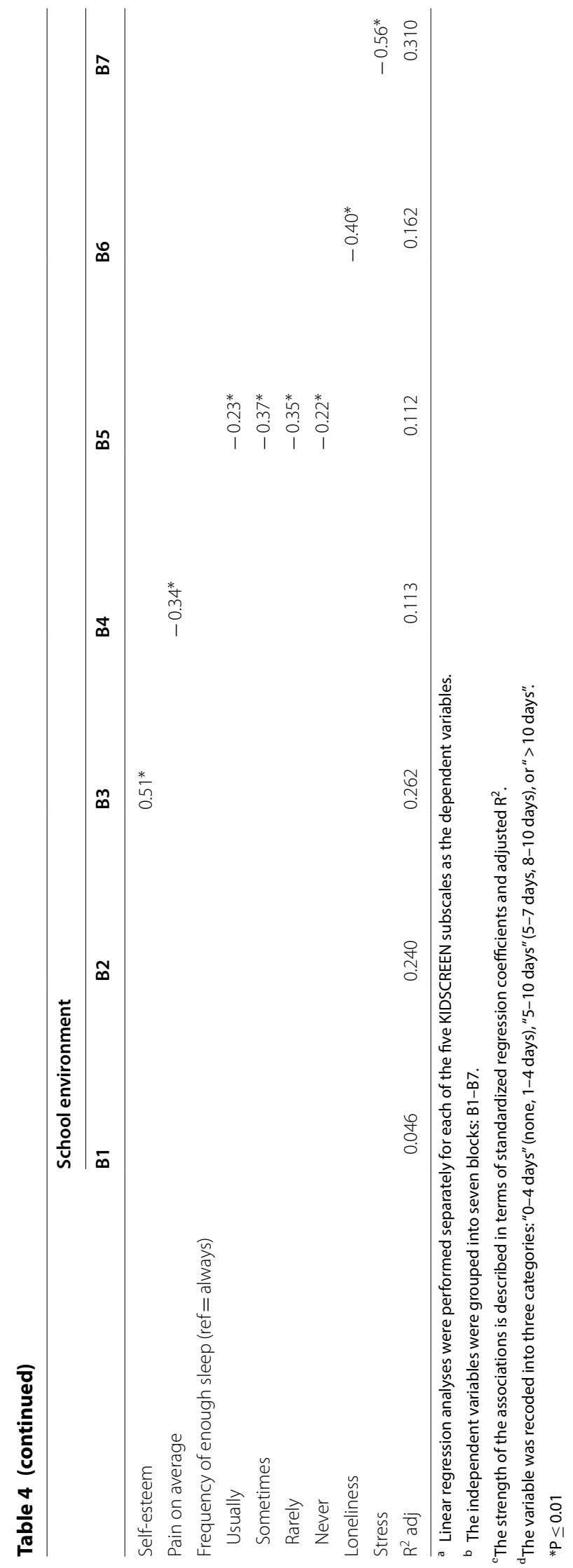




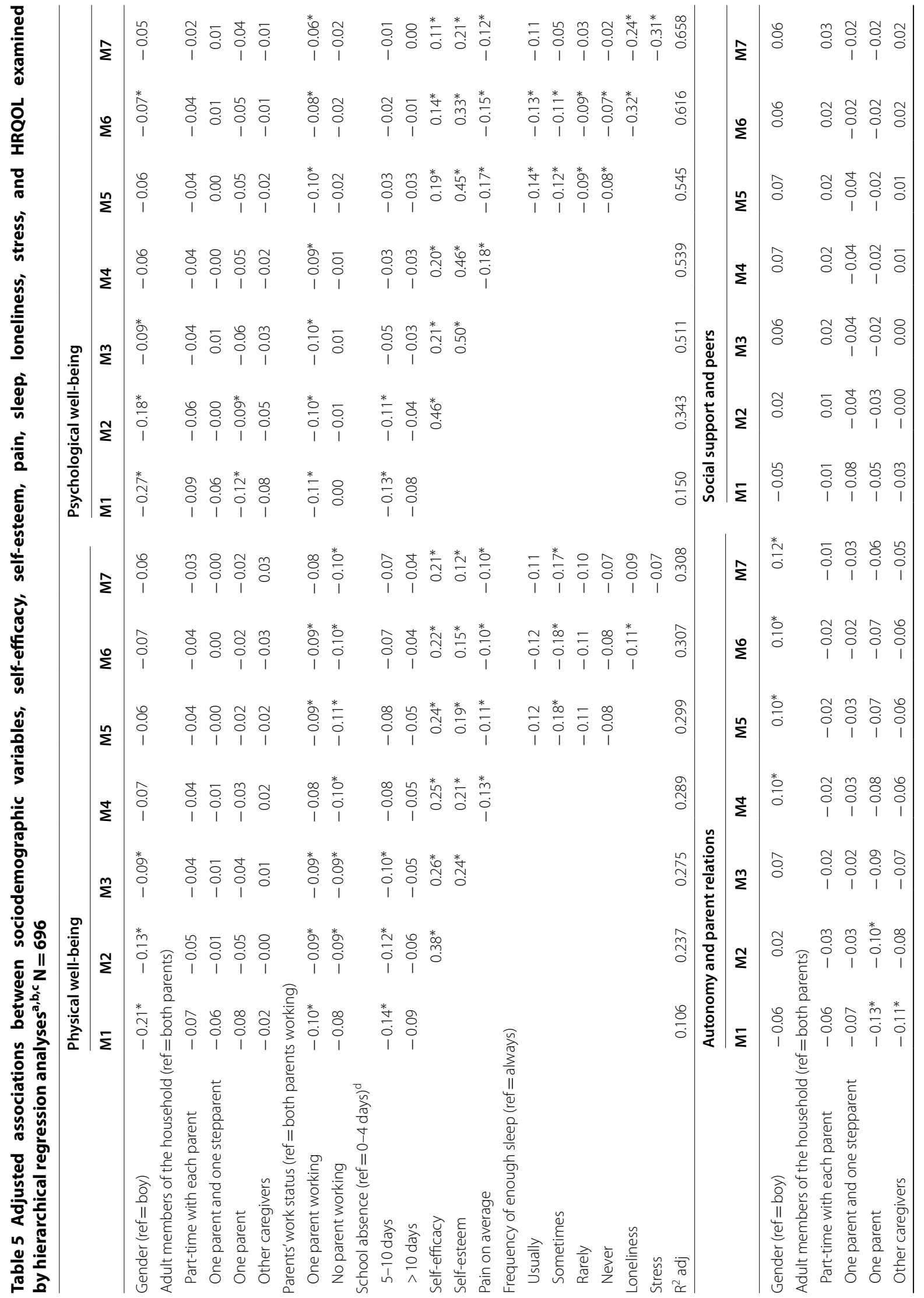




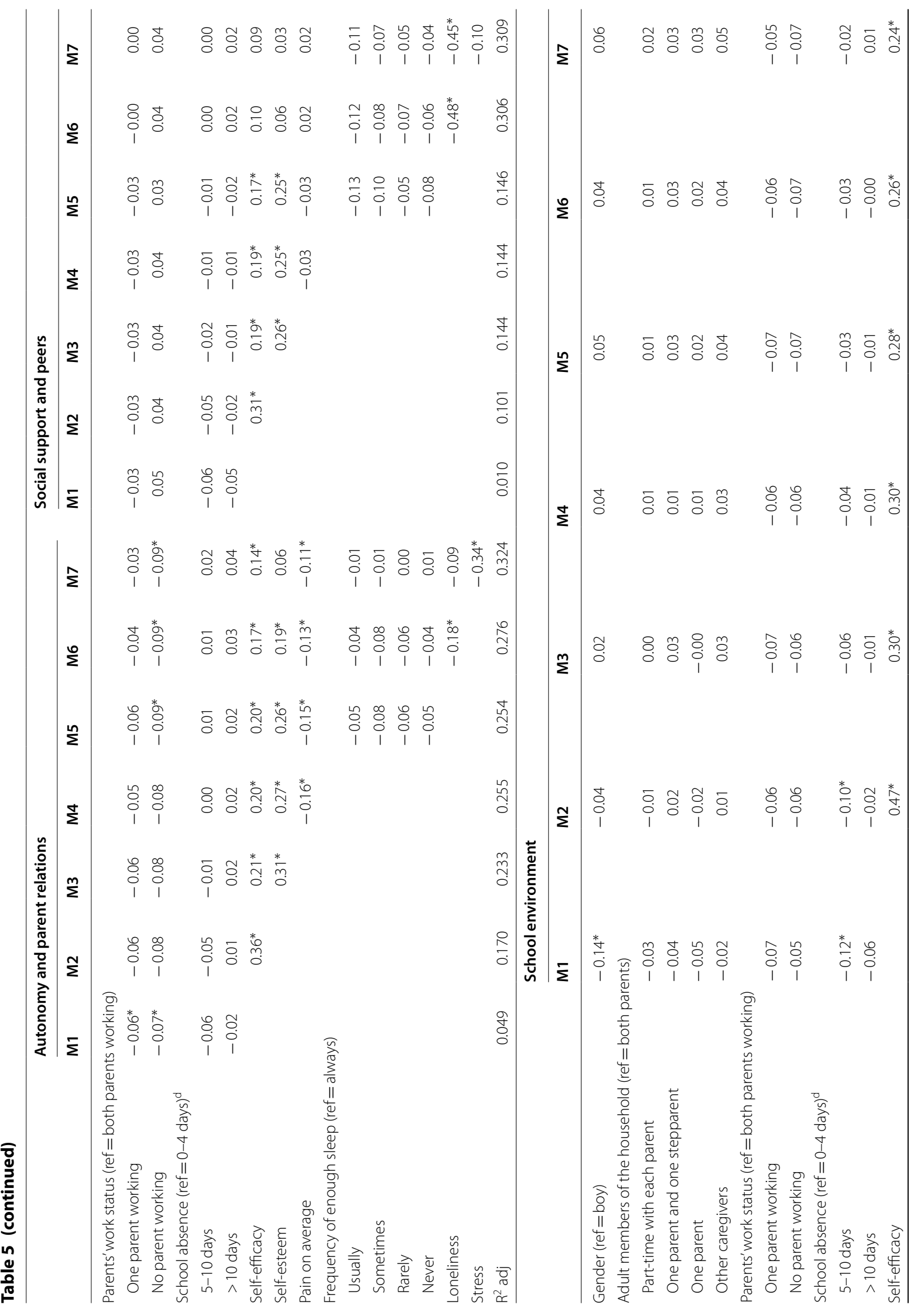




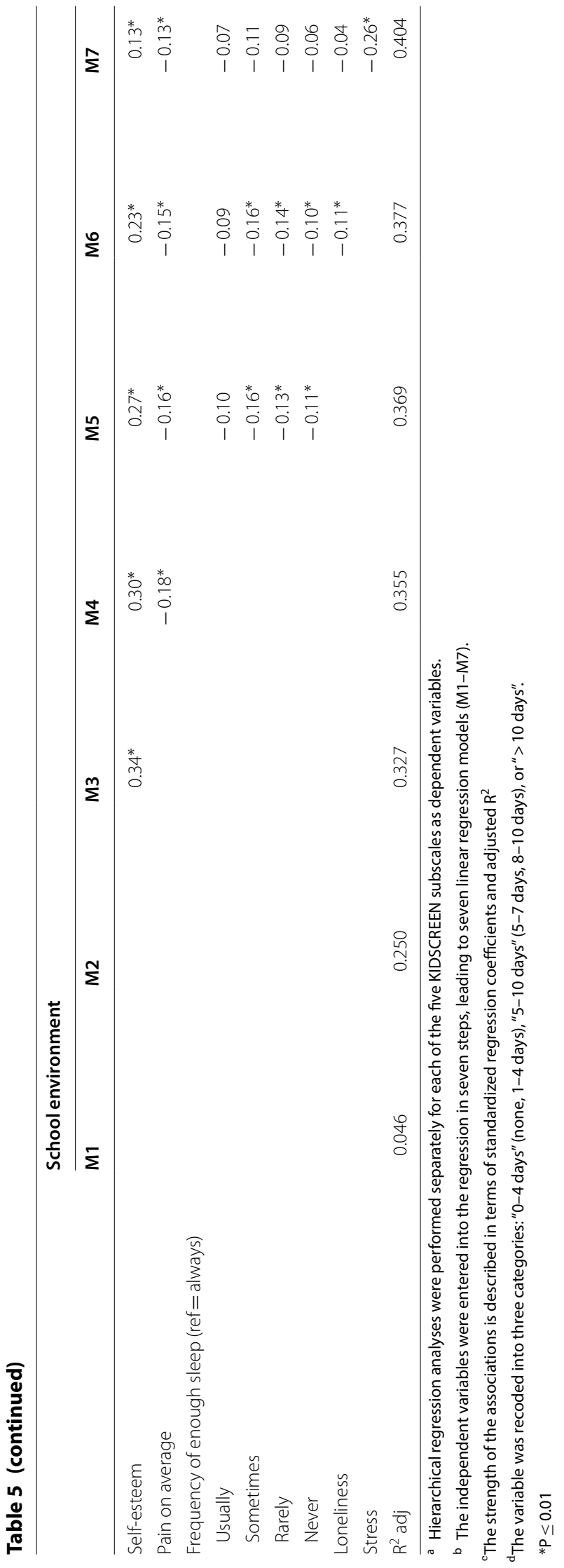




\section{Strengths and limitations}

The main strengths of this study include the relatively large sample of 14-15-year-old adolescents in a schoolbased setting, and that the selected analyzed variables were all assessed with well-validated instruments. The results of this study may be regarded as representative of adolescents in the south-eastern part of Norway; however, we do not know whether they can be generalized to the rest of Norway. Nevertheless, the school system in Norway is fairly homogeneous considering that the majority of adolescents are attending public schools [72], indicating that the findings should be similar for the same age group in other Norwegian regions. However, more than two thirds of the participants lived with both parents, had parents that were both born in Norway and had parents that were both working, indicating that the results may not be representative for adolescents that come from families with lower SES. This should be taken into consideration when interpreting our results.

This was a cross-sectional study, which makes it impossible to determine causal inference. Another limitation is linked to non-participation. Overall response rate was only $41.8 \%$, and we do not have information to assess whether the participants and nonparticipants differed in any respect. Still, it seems plausible that the use of active consent from parents may have resulted in a biased sample, considering the low response rate. Several adolescents said that they wanted to participate but had forgotten to ask their parents for consent or had forgotten to bring their parents' consent form at the time of data collection. We cannot assume if there were any differences between those who had the written consent or not. We may only speculate that parents with high education were more likely to deliver informed consent. However, due to General Data Protection Regulation laws we were not allowed to ask non-responders anything. Furthermore, we did not control for other possible confounders such as bullying and digital technology use. Hence, controlling for other confounders are recommended in future studies.

\section{Clinical implications and future research}

Overall, this study contributes to more knowledge of how sociodemographic variables, self-efficacy, self-esteem, pain, sleep, loneliness and stress are related to HRQOL in 14-15-year-old adolescents. To promote HRQOL among adolescents, we suggest that future interventions should prioritize their attention towards psychosocial factors. Interventions aimed at preventing negative psychosocial factors (e.g., stress), might be performed through the promotion of self-efficacy and self-esteem. Moreover, our findings indicate that to develop efficient HRQOLpromoting interventions, future studies should consider possible gender differences within factors that are associated with HRQOL. We encourage future research to use longitudinal designs to explore our findings more thoroughly. Considering that adolescents spend most of their time in school, we suggest the school setting as an important arena for HRQOL-promoting interventions.

\section{Conclusions}

In this cross-sectional study among 14-15-year-old adolescents in a school-based setting, we found that psychosocial factors (self-efficacy, self-esteem, loneliness, and stress) are more strongly associated with HRQOL, than sociodemographic-, pain-, and sleep-related factors. Our findings indicate that positive psychosocial factors such as self-efficacy and self-esteem might play a buffer role for negative psychosocial factors (e.g., stress) in adolescents. Furthermore, our results showed that girls score significantly worse on HRQOL, self-efficacy, self-esteem, pain, sleep, loneliness, and stress compared with boys. To improve HRQOL in school-based populations of adolescents, we suggest that future interventions should prioritize their attention towards psychosocial factors, especially towards a strengthening of the adolescents' self-efficacy and self-esteem. We recommend genderspecific interventions.

\section{Abbreviations \\ BPI: Brief Pain Inventory; GSE: General self-efficacy scale; HRQOL: Health- related quality of life; LPQ: Lübeck Pain-Screening Questionnaire; OTC analge- sics: Over-the-counter analgesics; PSQ: Perceived Stress Questionnaire; QOL: Quality of life; RSES: Rosenberg Self-Esteem scale; SES: Socioeconomic status; SUS: Pain, youth and self-medication study; ULS: UCLA Loneliness Scale; WHO: World Health Organization.}

\section{Acknowledgements}

We are grateful to all the adolescents who participated in the study and to all the teachers, school nurses and administrative school staff who made this study possible. We would also like to thank Anne Berit Rege, Hanne Hvidsten and Gunhild S. Øverbø for their valuable help.

\section{Authors' contributions}

All authors contributed to the study conception and design. HTM was responsible for the recruitment together with SS and GR. Data analysis were performed by HTM and MCS. The first draft of the manuscript was written by HTM and all authors commented on previous versions of the manuscript. All authors read and approved the final manuscript.

\section{Funding}

This study is part of the first author's doctoral thesis at the University of Agder and was financially supported by the Norwegian Ministry of Education and Research.

\section{Availability of data and materials}

The datasets used and/or analyzed during the current study are not publicly available due to General Data Protection Regulation laws but are available from the corresponding author on reasonable request and with permission from the Norwegian Centre for Research Data.

Ethics approval and consent to participate

The participants received oral and written information. Written information was also distributed to the parents. Informed consent was obtained from 
both the individual participants included in the study and their parents/legal guardians. Data in the study were anonymized. All procedures performed in the study were in accordance with the ethical standards of the institutional and/or national research committee and with the 1964 Helsinki declaration and its later amendments or comparable ethical standards. Approval was obtained from the ethics committee of Faculty of Health and Sport Sciences' at the University of Agder and from the Norwegian Centre for Research Data (NSD Reference 60981).

\section{Consent for publication}

Not applicable.

\section{Competing interests}

The authors declare that they have no competing interests.

\section{Author details}

1 Department of Health and Nursing, Faculty of Health and Sport Sciences, University of Agder, Postbox 422, 4604 Kristiansand, Norway. ${ }^{2}$ Department of Nursing and Health Promotion, Faculty of Health Sciences, Oslo Metropoli$\tan$ University, Oslo, Norway. ${ }^{3}$ Department of Clinical Research, Sorlandet Hospital, Kristiansand, Norway.

Received: 29 June 2020 Accepted: 29 September 2020

Published online: 02 November 2020

\section{References}

1. Fayers PM. Quality of life: The assessment, analysis and reporting of patient-reported outcomes. 3rd ed. Chichester: Wiley; 2016.

2. Ravens-Sieberer U, Erhart M, Wille N, Wetzel R, Nickel J, Bullinger M. Generic health-related quality-of-life assessment in children and adolescents. PharmacoEconomics. 2006a;24(12):1199-220.

3. Barnekow V, Currie C, Letsch C, de Looze M, Morgan A. A snapshot of the health of young people in Europe: a report prepared for the European Union Conference on Youth Health, Brussels, Belgium 9-10 July 2009. Copenhagen: WHO Regional Office for Europe; 2009.

4. World Health Organization. Global accelerated action for the health of adolescents (AA-HA!): Guidance to support country implementation. Geneva: World Health Organization; 2017.

5. World Health Organization. Coming of age: Adolescent health. 2019. https://www.who.int/health-topics/adolescents/coming-of-age-adole scent-health. Accessed 12 March 2019.

6. Sawyer SM, Afifi RA, Bearinger LH, Blakemore S-J, Dick B, Ezeh AC, Patton GC. Adolescence: A foundation for future health. Lancet. 2012;379:1630-40.

7. Moksnes UK, Moljord IEO, Espnes GA, Byrne DG. The association between stress and emotional states in adolescents: The role of gender and selfesteem. Pers Individ Differ. 2010;49:430-5.

8. Helseth S, Misvær N. Adolescents' perceptions of quality of life: what it is and what matters. J Clin Nurs. 2010;19:1454-61.

9. Høie M, Haraldstad K, Rohde G, Fegran L, Westergren T, Helseth S, Slettebø Å, Johannessen B. How school nurses experience and understand everyday pain among adolescents. BMC Nurs. 2017;16:53.

10. Babore A, Trumello C, Candelori C, Paciello M, Cerniglia L. Depressive symptoms, self-esteem and perceived parent-child relationship in early adolescence. Front Psychol. 2016;7:982.

11. Heinrich LM, Gullone E. The clinical significance of loneliness: a literature review. Clin Psychol Rev. 2006;26:695-718.

12. Skarstein $S$, Lagerløv P, Kvarme LG, Helseth S. High use of over-thecounter analgesic; possible warnings of reduced quality of life in adolescents-a qualitative study. BMC Nurs. 2016;15:16.

13. Bakken A. Ungdata. Nasjonale resultater 2018, NOVA Rapport 8/18. Oslo; 2018.

14. Osteras B, Sigmundsson $H$, Haga M. Pain is prevalent among adolescents and equally related to stress across genders. Scand J Pain. 2016;12:100-7.

15. Baroudi M, Petersen S, Namatovu F, Carlsson A, Ivarsson A, Norstrom F. Preteen children's health related quality of life in Sweden: changes over time and disparities between different sociodemographic groups. BMC Public Health. 2019;19:139.
16. Svedberg P, Eriksson M, Boman E. Associations between scores of psychosomatic health symptoms and health-related quality of life in children and adolescents. Health Qual Life Outcomes. 2013;11:176.

17. Skarstein S, Rosvold EO, Helseth S, Kvarme LG, Holager T, Smastuen MC, Lagerlov P. High-frequency use of over-the-counter analgesics among adolescents: reflections of an emerging difficult life, a cross-sectional study. Scand J Caring Sci. 2014;28:49-56.

18. Gobina I, Valimaa R, Tynjala J, Villberg J, Villerusa A, lannotti RJ, Godeau E, Gabhainn SN, Andersen A, Holstein BE, et al. The medicine use and corresponding subjective health complaints among adolescents, a crossnational survey. Pharmacoepidemiol Drug Saf. 2011;20:424-31.

19. Yeo SC, Jos AM, Erwin C, Lee SM, Lee XK, Lo JC, Chee MWL, Gooley JJ. Associations of sleep duration on school nights with self-rated health, overweight, and depression symptoms in adolescents: problems and possible solutions. Sleep Med. 2019;60:96-108.

20. Chaput JP, Gray CE, Poitras VJ, Carson V, Gruber R, Olds T, Weiss SK, Connor Gorber S, Kho ME, Sampson M, et al. Systematic review of the relationships between sleep duration and health indicators in school-aged children and youth. Appl Physiol Nutr Metab. 2016;41:S266-282.

21. Nygren $K$, Bergström E, Janlert U, Nygren L. Parents matter-but relations to parents do not explain gender differences in self-reported health in adolescents. Scand J Caring Sci. 2012;26:643-53.

22. Freire T, Ferreira G. Health-related quality of life of adolescents: Relations with positive and negative psychological dimensions. Int J Adolesc Youth. 2018;23:11-24.

23. Haraldstad K, Christophersen KA, Helseth S. Health-related quality of life and pain in children and adolescents: a school survey. BMC Pediatr. 2017;17(1):174.

24. Bisegger C, Cloetta B, von Bisegger U, Abel T, Ravens-Sieberer U. Healthrelated quality of life: gender differences in childhood and adolescence. Soz Praventivmed. 2005;50:281-91.

25. Otto C, Haller AC, Klasen F, Holling H, Bullinger M, Ravens-Sieberer U. Risk and protective factors of health-related quality of life in children and adolescents: results of the longitudinal BELLA study. PLOS ONE. 2017;12:e0190363.

26. Meade T, Dowswell E. Adolescents' health-related quality of life (HRQoL) changes over time: a three year longitudinal study. Health Qual Life Outcomes. 2016;14:14.

27. Langeland IO, Sollesnes R, Nilsen RM, Almenning G, Langeland E. Examining boys' and girls' health-related quality of life from the first to the third year of upper secondary school: A prospective longitudinal study. Nurs Open. 2019;6:1606-14.

28. McDougall J, Baldwin P, Evans J, Nichols M, Etherington N, Wright V. Quality of life and self-determination: youth with chronic health conditions make the connection. Appl Res Qual Life. 2016;11:571-99.

29. Rajmil L, Herdman M, Ravens-Sieberer U, Erhart M, Alonso J. Socioeconomic inequalities in mental health and health-related quality of life (HRQOL) in children and adolescents from 11 European countries. Int J Public Health. 2014;59:95-105.

30. Wu XY, Ohinmaa A, Veugelers PJ. Sociodemographic and neighbourhood determinants of health-related quality of life among grade-five students in Canada. Qual Life Res. 2010;19:969-76.

31. Gomes AC, Rebelo MAB, de Queiroz AC, de Queiroz Herkrath APC, Herkrath FJ, Rebelo Vieira JM, Pereira JV, Vettore MV. Socioeconomic status, social support, oral health beliefs, psychosocial factors, health behaviours and health-related quality of life in adolescents. Qual Life Res. 2020;29:141-51.

32. Gaspar T, Matos MG, Pais R, Jose L, Leal I, Ferreira A. Health-related quality of life in children and adolescents and associated factors. J Cogn Behav Psychother. 2009;9(1):33-48.

33. Haraldstad K, Kvarme LG, Christophersen KA, Helseth S. Associations between self-efficacy, bullying and health-related quality of life in a school sample of adolescents: a cross-sectional study. BMC Public Health. 2019;19:757.

34. Kvarme LG, Haraldstad K, Helseth S, Sorum R, Natvig GK. Associations between general self-efficacy and health- related quality of life among 12-13-year-old school children: a cross-sectional survey. Health Qual Life Outcomes. 2009;7:85.

35. Petersen S, Hagglof BL, Bergstrom El. Impaired health-related quality of life in children with recurrent pain. Pediatrics. 2009;124(4):e759-67. 
36. Haraldstad K, Christophersen K-A, Eide H, Nativg GK, Helseth S. Predictors of health-related quality of life in a sample of children and adolescents: a school survey. J Clin Nurs. 2011;20:3048-56.

37. Ravens-Sieberer U, Erhart M, Wille N, Wetzel R, Nickel J, Bullinger M. Generic health-related quality-of-life assessment in children and adolescents: methodological considerations. Pharmacoeconomics. 2006b;24:1199-220.

38. Roeser K, Eichholz R, Schwerdtle B, Schlarb AA, Kübler A. Relationship of sleep quality and health-related quality of life in adolescents according to self- and proxy ratings: a questionnaire survey. Front Psychiatry. 2012;3:76.

39. Gustafsson ML, Laaksonen C, Aromaa M, Asanti R, Heinonen OJ, Koski P, Koivusilta L, Loyttyniemi E, Suominen S, Salantera S. Association between amount of sleep, daytime sleepiness and health-related quality of life in schoolchildren. J Adv Nurs. 2016;72:1263-72.

40. Pallant J. SPSS survival manual: a step by step guide to data analysis using IBM SPSS. 6th ed. Maidenhead: McGraw Hill Education; 2016.

41. Ravens-Sieberer U, Auquier P, Erhart M, Gosch A, Rajmil L, Bruil J, Power M, Duer W, Cloetta B, Czemy L, et al. The KIDSCREEN-27 quality of life measure for children and adolescents: psychometric results from a crosscultural survey in 13 European countries. Qual Life Res. 2007;16:1347-56.

42. Andersen JR, Natvig GK, Haraldstad K, Skrede T, Aadland E, Resaland GK. Psychometric properties of the Norwegian version of the Kidscreen-27 questionnaire. Health Qual Life Outcomes. 2016;14:58.

43. Ravens-Sieberer U, Herdman M, Devine J, Otto C, Bullinger M, Rose M, Klasen F. The European KIDSCREEN approach to measure quality of life and well-being in children: development, current application, and future advances. Qual Life Res. 2014;23:791-803.

44. Robitail S, Ravens-Sieberer U, Simeoni MC, Rajmil L, Bruil J, Power M, Duer W, Cloetta B, Czemy L, Mazur J, et al. Testing the structural and crosscultural validity of the KIDSCREEN-27 quality of life questionnaire. Qual Life Res. 2007:16:1335-45.

45. The KIDSCREEN Group Europe. The KIDSCREEN questionnaires- quality of life questionnaires for children and adolescents. Handbook. Lengerich: Pabst Science Publishers; 2006.

46. Luszczynska A, Scholz U, Schwarzer R. The general self-efficacy scale: multicultural validation studies. J Psychol. 2005;139:439-57.

47. Bonsaksen T, Lerdal A, Heir T, Ekeberg O, Skogstad L, Grimholt TK, SchouBredal I. General self-efficacy in the Norwegian population: differences and similarities between sociodemographic groups. Scand J Public Health. 2019;47:695-704.

48. Rosenberg M. Society and the adolescent self-image. Princeton: Princeton University Press; 1965

49. Tambs K, Røysamb E. Selection of questions to short-form versions of original psychometric instruments in MoBa. Norsk epidemiologi. 2014;24:195-201.

50. Stensland SØ, Thoresen S, Wentzel-Larsen T, Dyb G. Interpersonal violence and overweight in adolescents: The HUNT Study. Scand J Public Health. 2015;43:18-26.

51. Derdikman-Eiron R, Indredavik MS, Bratberg GH, Taraldsen G, Bakken IJ, Colton M. Gender differences in subjective well-being, self-esteem and psychosocial functioning in adolescents with symptoms of anxiety and depression: findings from the Nord-Trondelag health study (Clinical report). Scand J Psychol. 2011;52:261-7.

52. Cleeland CS, Ryan KM. Pain assessment: global use of the Brief Pain Inventory. Ann Acad Med Singapore. 1994;23:129-38.

53. Klepstad P, Loge JH, Borchgrevink PC, Mendoza TR, Cleeland CS, Kaasa S. The Norwegian brief pain inventory questionnaire: translation and validation in cancer pain patients. J Pain Symptom Manage. 2002;24:517-25.

54. Roth-Isigkeit A, Thyen U, Raspe HH, Stoven H, Schmucker P. Reports of pain among German children and adolescents: an epidemiological study. Acta Paediatr. 2004;93:258-63.
55. Winger A, Kvarstein G, Wyller VB, Sulheim D, Fagermoen E, Smastuen MC, Helseth $S$. Pain and pressure pain thresholds in adolescents with chronic fatigue syndrome and healthy controls: a cross-sectional study. BMJ Open. 2014;4:e005920.

56. Haraldstad K, Sorum R, Eide H, Natvig GK, Helseth S. Pain in children and adolescents: prevalence, impact on daily life, and parents' perception, a school survey. Scand J Caring Sci. 2011;25:27-36.

57. Lagerlov P, Holager T, Helseth S. Rosvold EO [Self-medication with overthe-counter analgesics among 15-16 year-old teenagers]. Tidsskr Nor Laegeforen. 2009;129:1447-50.

58. Wolfson AR, Carskadon MA. Sleep schedules and daytime functioning in adolescents. Child Dev. 1998;69:875-87.

59. Wolfson AR, Carskadon MA, Acebo C, Seifer R, Fallone G, Labyak SE, Martin $J$ L. Evidence for the validity of a sleep habits survey for adolescents. Sleep. 2003;26:213-6.

60. Pallesen S, Saxvig IW, Molde H, Sørensen E, Wilhelmsen-Langeland A, Bjorvatn B. Brief report: behaviorally induced insufficient sleep syndrome in older adolescents: prevalence and correlates. J Adolesc. 2011;34:391-5.

61. Hays RD, DiMatteo MR. A short-form measure of loneliness. J Pers Assess. 1987:51:69-81.

62. Russell D, Peplau LA, Cutrona CE. The revised UCLA Loneliness Scale: concurrent and discriminant validity evidence. J Pers Soc Psychol. 1980;39:472-80.

63. Yildiz M, Duy B. Adaptation of the short-form of the UCLA Loneliness Scale (ULS-8) to Turkish for the Adolescents. Dusunen Adam. 2014;27:194-203.

64. Wilson D, Cutts J, Lees I, Mapungwana S, Maunganidze L. Psychometric properties of the revised UCLA Loneliness Scale and two short-form measures of loneliness in Zimbabwe. J Pers Assess. 1992:59:72-81.

65. World Health Organization. Process of translation and adaptation of instruments; 2019. https://www.who.int/substance_abuse/research_ tools/translation/en/. Accessed 15 Nov 2019.

66. Levenstein S, Prantera C, Varvo V, Scribano ML, Berto E, Luzi C, Andreoli A. Development of the Perceived Stress Questionnaire: a new tool for psychosomatic research. J Psychosom Res. 1993;37:19-32.

67. Kocalevent RD, Levenstein S, Fliege H, Schmid G, Hinz A, Brahler E, Klapp BF. Contribution to the construct validity of the Perceived Stress Questionnaire from a population-based survey. J Psychosom Res. 2007;63:71-81.

68. Østerås B, Sigmundsson H, Haga M. Psychometric properties of the perceived stress questionnaire (PSQ) in 15-16 Years old Norwegian adolescents. Front Psychol. 2018:9:1850-1850.

69. Østerås B, Sigmundsson H, Haga M. Physical fitness levels do not affect stress levels in a sample of Norwegian Adolescents. Front Psychol. 2017;8:2176-2176.

70. Skarstein S, Lagerlov P, Helseth S, Leegaard M. How do parents influence their adolescents' use of over-the-counter analgesics: A review of the current literature. J Clin Nurs. 2019;28:1451-64.

71. Gradisar M, Gardner G, Dohnt H. Recent worldwide sleep patterns and problems during adolescence: a review and meta-analysis of age, region, and sleep. Sleep Med. 2011;12:110-8.

72. Statistics Norway. Facts about education in Norway 2020-key figures 2018. Oslo: Statistics Norway; 2019

\section{Publisher's Note}

Springer Nature remains neutral with regard to jurisdictional claims in published maps and institutional affiliations. 